\section{Public Health in Great Britain}

IN his annual report for 1936, published last week, Sir Arthur MacNalty, Chief Medical Officer of the Ministry of Health, points out that this year of the Coronation is also the centenary of Queen Victoria's accession, and he takes the opportunity to present an impressive statement of the remarkable progress that has been made in national health and in medicine in the past hundred years and of the amazing decline in mortality rates during that period. For 1936, the crude death-rate was $12 \cdot 1$ per 1,000 living, compared with 22.4 in the eighteen forties, the infant mortality rate was 59 as against 153, and the number of infants who died at less than one year of age was 35,425less than half the number who would have died under conditions of as little as thirty years ago. The standardized death-rate from tuberculosis, respiratory and non-respiratory, was 657 per million living, compared with an average of 3,476 in the fifties of last century. There is an increase in the mortality from cancer, the number of deaths being 66,354, an increase of 1,847 on the previous year, which is a larger increase than that in 1935 over 1934. The maternal mortality rate was $3 \cdot 8$ per 1,000 live births, the lowest recorded since 1923. Reference is made to the importance of the consumption of a sufficient quantity of milk, described as "the key to proper nutrition", and commendation is expressed for properly operated milk bars. The report points out the risk of skin affections from the use of certain sub. stances in lip-stick, hair-dye, face cream and other cosmetics, but observes that untoward results are relatively very few. Reference is made, in conclusion, to the national health services, the need for knowledge of these services, and to the intensive national health campaign organized and launched this auturnn.

\section{Photo-electric Control in Industry}

AT the Nottingham meeting of the British Association, Mr. A. L. Whiteley contributed to Section A a paper on photo-electric control in industry. The photo-electric cell provides greater rapidity of action and a higher sensitivity than other light-sensitive devices. The greatest field for it is the talking picture industry, but this does not come under the subject of his paper. In industry the cells are usually made in standard sets called photo-electric relays, containing an amplifier circuit and a small contactor capable of making or breaking 15 amperes. An obvious application of this unit is counting objects on a conveyor belt or vehicles passing on a road. It can easily be used to make the pointer of an instrument actuate an external circuit on reaching a pre. determined scale reading. Applications of this nature include automatic weighing of mass-produced parts and automatic termination of operations on high precision grinders when a mechanical gauge records that a certain diameter of the part operated on has been reached. It is also used to control street lighting according to variations in the intensity of the light. In many types of automatic wrapping and bagmaking machines a continuous preprinted web of paper or "Cellophane" is fed to the machine at a high speed. It is necessary that positional relation. ship between the printed matter and the fold or cut be maintained. This is done by the response of the printed matter itself. The system is used abroad to maintain 'register' between the design and the perforations of postage stamps. It can be applied to record the intensity of the smoke coming from a chimney and the temperature of strip steel as it comes from the hot rolls of a rolling mill.

\section{Blood Groups in Central Africa}

Mr. R. Elsdon-Dew, of the South African Institute for Medical Research, Johannesburg, has recently returned from his six months' expedition to Central Africa for research on the blood-grouping of the various native inhabitants of this region. In a communication to the Editor, he has included a long table of percentages based on his observations, for which space cannot be found. His investigations covered tribes of Rhodesia, Nyasaland, Tanganyika, Kenya and Uganda, reaching so far north as to the Nilotic peoples of the lowlands to the north-east of the great lakes. In all, thirty-four tribes or groups of peoples were examined, the numbers in each group ranging from one hundred and twenty-three (Tumbuka) to five hundred and seventy-six (Yao). In the majority of instances, however, the numbers were between four and five hundred, thus approximating in size to the eleven groups of natives of South Africa previously reported (see NATURE, July 10, 1937, p. 77), each of which numbered five hundred. These later results have not yet been analysed, so that any inference from the observations would be premature; but the percentages of the groups already worked out suggest that the analysis, when completed by Mr. Elsdon-Dew, will prove not only of great serological interest, but will also afford material of considerable significance for the ethnologist. These percentages follow the results of the earlier investigation in suggesting a striking tendency to the predominance of the $O$ group among Bantuspeaking peoples. In the thirty-four sets of observations, the $O$ group is less than 50 per cent in six instances only. In fourteen it ranges from 50 to 60 per cent, in twelve from 60 per cent to 70 per cent, and in two it is more than 70 per cent. Among the Wagogo the grouping is : $O, 73 \cdot 1 ; A, 19 \cdot 6 ; B, 5 \cdot 8$; $A B, 1.6$; among the Vandau: $O, 74.4 ; A, 13.4$; $B, 10.4 ; A B, 1.8$. The highest percentage of $A$ appears in the Wakamba: $O, 53.3 ; A, 31.8$; $B, 12.9 ; A B, 2 \cdot 0$; and the highest $B$ among the Lango (Nilote) : $O, 41 \cdot 1 ; A, 27 \cdot 6 ; B, 28.9 ; A B$, $2 \cdot 4$.

\section{Cables for 200,000 volt Pressures}

For several years, research has been made in the laboratories of Callender's Cable Company with the object of designing an underground cable which will withstand the high electric pressures necessary for the economic transmission of electric energy over considerable distances. The new impregnated cable has now undergone a continuous test of 5,000 hours at 200 kilovolts and the application of numerous heat cycles during this period. According to the Electrician of November 19, it has also passed through the 